\title{
Feeding habits of American mink from Biebrza Wetlands affected by varied winter conditions
}

\section{Michał Skierczyński ${ }^{1, *}$, Anna Wiśniewska ${ }^{1}$ and Krystyna Stachura-Skierczyńska ${ }^{2}$}

${ }^{1}$ Department of Behavioural Ecology, Faculty of Biology, Adam Mickiewicz University, Umultowska 89, PL-61-614 Poznań, Poland,

e-mail: michskie@amu.edu.pl

2 Polish Society for the Protection of Birds (OTOP), Odrowąża 24, PL-05-270, Marki k. Warszawy, Poland

${ }^{*}$ Corresponding author

Keywords: American mink; Biebrza Wetlands; feeding habits; Neovison vison.

In general, American mink (Neovison vison) is described as an opportunistic predator, feeding mainly on mammals, fishes and amphibians, but also on birds and invertebrates (Lode 1993, Halliwell and Macdonald 1996, Jędrzejewska, et al. 2001, Sidorovich et al. 2001, Macdonald 2002, Bartoszewicz and Zalewski 2003). The diet of this predator can vary between spring-summer and autumn-winter seasons and is related to prey distribution under different habitat conditions (Sidorovich 2000, Jędrzejewska et al. 2001, Macdonald 2002). The subject of interactions between American mink and native European predator species such as the otter Lutra lutra (Bonesi and Macdonald 2004a,b, Bonesi et al. 2004), European mink Mustela lutreola (Maran et al. 1998, Lode et al. 2001, Sidorovich 2001, Sidorovich et al. 2001) and polecat Mustela putorius (Lode 1993), as well as long-term negative impacts on water ecosystems (Macdonald and Harrington 2003, Bonesi and Palazon 2007) have been widely discussed in the literature. Nevertheless, there is still not enough information about changes in diet for this predator under winter conditions in relation to prey availability (Bonesi et al. 2000). The winter period in Northern and Central-Eastern Europe is a "starvation season" for most predators. Unlike in spring, summer and autumn, prey availability is limited because of low temperatures, snow and ice. Small mammals and amphibians are hardly available, and ice cover on rivers allows hunting for fish only in open water spots.

Considering the facts known about this species, we can expect potential factors that will affect the feeding habits of American mink: (1) size of the river (Jędrzejewska et al. 2001); (2) ice cover distribution and distance to open water as a measure of fish availability; (3) distribution of beaver settlements where amphibians are hibernating during winter (Sidorovich 1997); (4) distance to built-up areas (a main source of domestic birds); and
(5) accessibility to small mammals (meadows and river banks).

The study plot was located in northeast Poland $\left(52^{\circ} 34^{\prime}\right.$ $\left.\mathrm{N}, 14^{\circ} 43^{\prime} \mathrm{E}\right)$, in Biebrza Wetlands. Research was conducted along the banks of two rivers: the Biebrza River (Biebrza area) and the Wissa River (Wissa area). The main differences between these two areas involve: (1) river size and catchment area (catchment area 13-fold greater for Biebrza than for Wissa); and (2) water slope, which affects water speed $(0.13 \%$ o for Biebrza and $1.60 \%$ ofor Wissa). The study area is covered by several different vegetation types, including semi-natural communities of humid and dry grasslands, meadows and sedge associations. Habitat characteristics vary considerably between years, depending on water levels and total overflow area. Data on mink distribution and diet were collected in three winter periods (2005-2007) under different conditions (temperature, water level, snow and ice cover) for each year (Figure 1).

Data on numbers and home ranges of individuals were obtained by snow tracking using GPS mapping on a single continuous $21-\mathrm{km}$ transect along the river banks. Live trapping was also conducted in winters of 2005 and 2006 between January and March, but not in 2007 because of harsh conditions (low temperature, strong wind and problems with the use of traps on frozen ground). Wooden and metal box traps with fish bait were set at ground level near the water at $200-\mathrm{m}$ to $1-\mathrm{km}$ intervals along the river bank. Trapping was continued for 10-20 days (depending on weather conditions) and traps were checked twice a day. Captured mink were sexed, weighed and individually marked with ear notches. The home range of each individual and other measurements such as the shortest distance from the centre of each home range to open water, built-up areas and beaver settlements were calculated using ArcView 3.2a. To obtain data on diet composition, scat samples were collected in $2005(n=46), 2006(n=60)$ and $2007(n=44 ; 150$ in total) and analysed. Prey remains were weighed $(0.01 \mathrm{~g}$ accuracy) and divided into five groups: invertebrates, fish, amphibians, birds and mammals. The relative biomass of each prey group in the diet of mink was calculated on the basis of dry mass of prey remains and digestion coefficient (Brzeziński and Marzec 2003). To estimate differences in diet, we used niche breadth $B$ (Levins 1968) and niche overlap $\alpha$ (Pianka 1973). A Gtest was used to compare differences in diet components between years and rivers, excluding invertebrates because of their insignificant levels (0-2\%).

Numbers of American mink recorded between the winter seasons of 2005 and 2006 did not differ much (8 and 7 individuals, respectively). In winter 2007, only three 


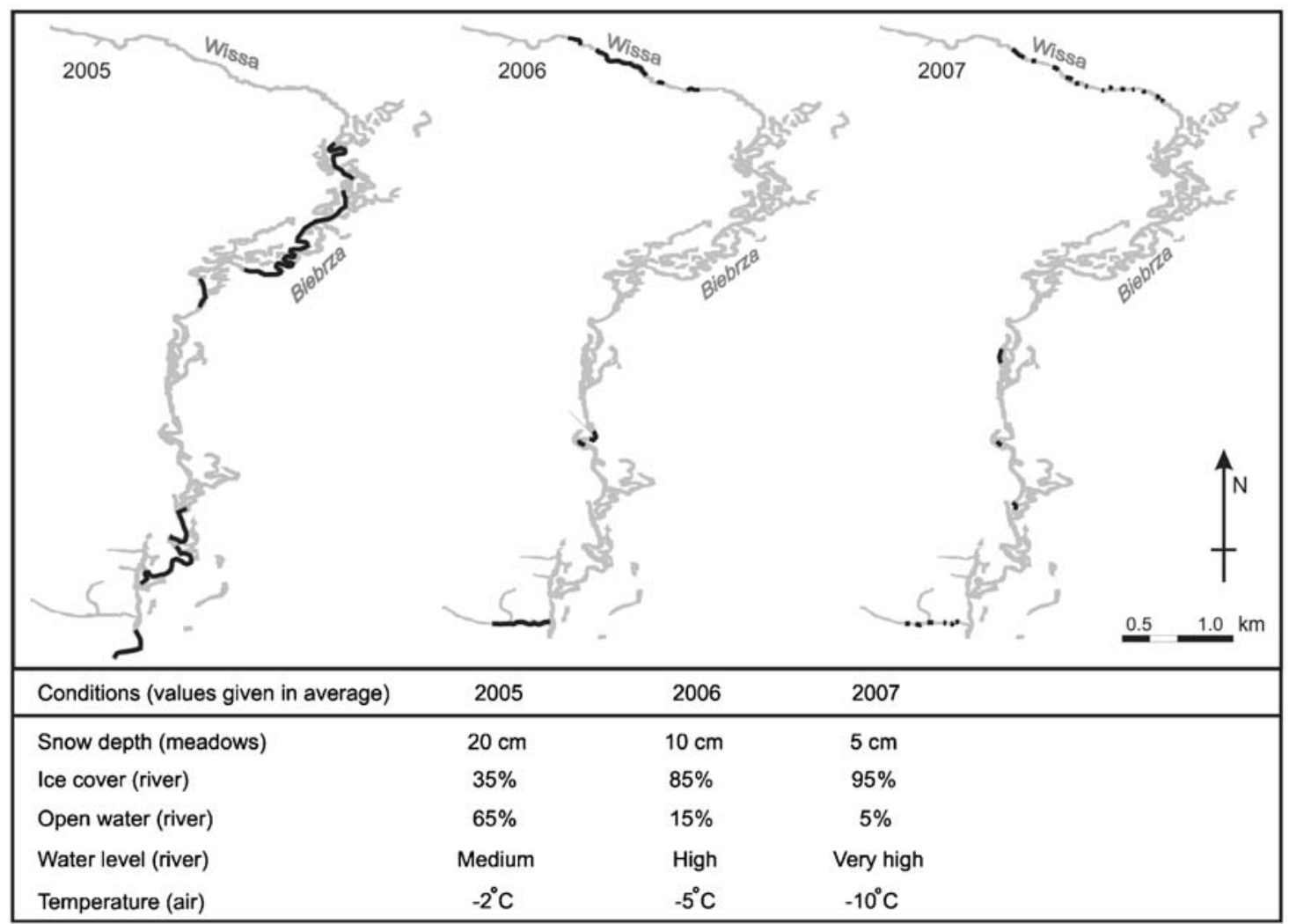

Figure 1 Winter conditions in three winter periods studied: distribution of ice cover in 2005 and open water in 2006 and 2007 (black line) on two rivers.

individuals were found. Their abundance varied between 3.8 and 1.4 individuals $/ 10 \mathrm{~km}$ of water line. In 2005 , the distance between centres of mink territories and open water was relatively small (Biebrza $10 \pm 2 \mathrm{~m}, \mathrm{n}=4$; Wissa $7 \pm 2 \mathrm{~m}, \mathrm{n}=4$ ), compared to 2006 (Biebrza 490 $\pm 212 \mathrm{~m}$, $\mathrm{n}=4$; Wissa $60 \pm 9 \mathrm{~m}, \mathrm{n}=3$ ). The distance to beaver settlements for both areas in 2005 (Biebrza 125 $\pm 53 \mathrm{~m}, \mathrm{n}=4$; Wissa 1564 $\pm 756 \mathrm{~m}, \mathrm{n}=4$ ) and 2006 (Biebrza $81 \pm 34 \mathrm{~m}$, $\mathrm{n}=4$; Wissa $1366 \pm 711 \mathrm{~m}, \mathrm{n}=3$ ) was rather stable between years and was much smaller for Biebrza than for Wissa. A similar situation was observed for distance to built-up areas (2005: Biebrza 241 $\pm 117 \mathrm{~m}, \mathrm{n}=4$; Wissa 1630 $\pm 605 \mathrm{~m}, \mathrm{n}=4$; 2006: Biebrza 415 $\pm 219 \mathrm{~m}, \mathrm{n}=4$; Wissa $1331 \pm 601 \mathrm{~m}, \mathrm{n}=3$ ). Meadow structure in the study area was similar for both rivers; however, accessibility to small mammals varied in each year because of differences in snow cover depth.

Each prey type, except for invertebrates, was well represented in the diet of American mink, but the proportion of particular components varied significantly between years and rivers (Table 1). In general, for the whole study area and study period, the main prey were fish and mammals $(G=20.977$, $d f=3, p<0.001)$. However, results differed between the two studied areas. The main prey groups for Biebrza were amphibians and mammals $(G=8.237, d f=3, p=0.041)$, whereas fish and mammals were the dominant prey for Wissa $(G=88.381$, $d f=3$, $p<0.001$ ). Comparison of the mink diet composition for

Table 1 Diet of American mink during three winter periods on both rivers studied.

\begin{tabular}{|c|c|c|c|c|c|c|}
\hline \multirow[t]{2}{*}{ River } & \multirow[t]{2}{*}{ Year } & \multicolumn{5}{|c|}{ Prey type (\% biomass) } \\
\hline & & Invertebrate & Fishes & Amphibians & Birds & Mammals \\
\hline \multirow[t]{4}{*}{ Biebrza } & 2005 & - & 17 & 82 & - & 1 \\
\hline & 2006 & 1 & 34 & 2 & 44 & 19 \\
\hline & 2007 & 1 & 2 & - & 12 & 85 \\
\hline & Average & 1 & 18 & 28 & 18 & 35 \\
\hline \multirow[t]{4}{*}{ Wissa } & 2005 & - & 84 & 16 & - & - \\
\hline & 2006 & 2 & 47 & - & 5 & 46 \\
\hline & 2007 & 1 & 16 & - & 2 & 81 \\
\hline & Average & 1 & 49 & 5 & 2 & 43 \\
\hline \multirow[t]{4}{*}{ Biebrza+Wissa } & 2005 & - & 50 & 49 & - & 1 \\
\hline & 2006 & 1 & 40 & 1 & 25 & 33 \\
\hline & 2007 & 1 & 9 & - & 7 & 83 \\
\hline & Average & 1 & 33 & 17 & 10 & 39 \\
\hline
\end{tabular}


2005-2007 over the whole study area revealed several differences between years: mink preyed mostly on fish and amphibians in 2005, on fish and mammals in 2006 and mostly on mammals in 2007 (Table 1). Similar trends were observed for Biebrza and Wissa areas separately. In 2005, the mink diet consisted mostly of amphibians in Biebrza and fish in Wissa, whereas in 2007 mammals were the dominant prey on both rivers. In 2006 the diet composition was more diverse (Table 1). During the study period there were no significant differences in the occurrence of mammals in the diet of individuals from Biebrza and Wissa, except in 2006, when this type of prey was taken mainly by mink from the Wissa river $(G=11.562$, $\mathrm{df}=1, \mathrm{p}<0.001$ ).

The niche breadth coefficient for American mink under winter conditions was rather low, and slightly greater for Biebrza than for Wissa (Table 2). During 2005 and 2006 we observed almost the same $B$ value for Biebrza, but this decreased drastically in 2007. On the other hand, $B$ values were almost stable during all three winter seasons for Wissa. The niche identity coefficient for American mink varied considerably between areas and years (Table 2 ). We found that $\alpha$ values increased with years, compared to niche identity of predators from Biebrza and Wissa areas, with almost identical value in winter 2007. For Biebrza area we observed a greater niche shift between 2006 and 2007 compared to 2005 vs. 2006 and 2005 vs. 2007. A similar situation was observed for Wissa, but the niche shift between 2005 and 2006 was greater compared to 2007.

The winter diet composition for American mink consisted of four main prey groups: fish, amphibians, birds and mammals. Invertebrates were a minor component and did not significantly affect the diet composition. Similar feeding habits during winter have been reported in other studies (e.g., Jędrzejewska et al. 2001). Our results suggest that the availability of particular prey groups differed between rivers in each year of the study, depending on the river size, total area of ice cover and snow cover depth. When there is little or no ice cover and the temperature is relatively high, fish hunting is very easy and effective. Thus, fishes were one of the main sources of food for mink in winter 2005 on both rivers. The area of ice cover is negatively correlated with the number of open water spots (suitable fish hunting places) and therefore affects the home range and distribution of minks. As

Table 2 Comparison of niche identity $\alpha_{i j}$ and niche breadth $B$ for American mink between rivers and years.

\begin{tabular}{lllll}
\hline Variable & Comparison & $\alpha_{i j}$ & Year & $B$ \\
\hline Biebrza & 2005 vs. 2006 & 0.16 & 2005 & 2.27 \\
& 2006 vs. 2007 & 0.43 & 2006 & 2.93 \\
& 2005 vs. 2007 & 0.01 & 2007 & 1.36 \\
& Mean & & & 2.19 \\
Wissa & 2005 vs. 2006 & 0.68 & 2005 & 1.36 \\
& 2006 vs. 2007 & 0.84 & 2006 & 1.40 \\
& 2005 vs. 2007 & 0.19 & 2007 & 1.45 \\
& Mean & & & 1.40 \\
2005 & Biebrza vs. Wissa & 0.38 & & \\
2006 & Biebrza vs. Wissa & 0.68 & & \\
2007 & Biebrza vs. Wissa & 0.98 & & \\
\hline
\end{tabular}

a result, either an individual has to switch very often between currently open water spots (sometimes spread over a distance of a few $\mathrm{km}$ ) or decides to use only one or two open water spots and protects them from freezing. Sometimes mink also use Eurasian otter hunting spots (Bonesi et al. 2000). Both strategies were observed during winter 2006 and 2007. Nevertheless, at low temperatures these are not efficient approaches in the long term. Both in 2006 and 2007, large area of ice cover was observed (compared to 2005), but the range and distribution were different for the two rivers. There were more open water spots, and therefore a greater probability of successful fish hunting, on the Wissa river than on the Biebrza. During mild winters, amphibians hibernating inside beaver settlements (Sidorovich 1997) and in river banks are easy to hunt once the predator has located them. This prey group was exploited by American mink during winter 2005 (small area of ice cover, relatively high temperatures), but mostly in Biebrza (82\% of the diet). During winters 2006 and 2007 the area of ice cover was greater compared to 2005, resulting in poor availability of amphibians, since the banks of both rivers and areas around beaver settlements were covered with thick ice. As a consequence, a significant decrease in the proportion of amphibians in the diet of American mink was observed for both rivers. Similar results observed during very cold winters have been reported for this predator (Jędrzejewska et al. 2001). Bird remains recorded in scat samples were mostly domestic species (hens, pigeons and ducks), but also included tits (Parus spp.) and sparrows (Passer spp.). The proportion of birds in the American mink diet differed significantly between the two rivers studied, and was higher for the Biebrza. This difference is closely related to the distance from mink territories to built-up areas, which was generally smaller for Biebrza than for Wissa. Hunting for mammals, including locating prey and overcoming anti-predatory strategies, is an exhaustive process that imposes high energetic costs on the predator (Krebs 1994, Krebs and Davies 2001, Lima et al. 2003, Fey et al. 2006). The availability of this prey group during winter is also related to green biomass productivity during summer, thickness of snow cover and predation by other competitors such as raptors. Wet meadows provide optimal conditions for small mammals such as the water vole Arvicola terrestris and the root vole Microtus oeconomus (Barreto et al. 1998, Rushton et al. 2000, Forman 2005), but as we observed, this type of prey appears in the diet of American mink only when the availability of other prey groups decreases. As a result, the proportion of mammals in the diet of American mink during winter increases in harsh conditions (low temperatures and large ice cover).

In general, during winter the niche breadth for American mink was narrow, which is typical for this predator (Bonesi et al. 2004). Interestingly, individuals that occupied neighbouring rivers showed different feeding habits, but during colder winters the changes in dietary habits followed similar trends for both areas: a decrease in the proportions of fish and amphibians in favour of mammals. Similar results have been reported for American mink (Maran et al. 1998, Sidorovich 2000, Macdonald 2002, Bonesi and Macdonald 2004b) and other predators 
such as European polecat (Lode 1995, 1997, 2000, Sidorovich 2000, Macdonald 2002) and river otter (Sidorovich 2000, Macdonald 2002, Bonesi and Macdonald 2004b). The most interesting fact observed during the present study was that mink occupying neighbouring rivers showed different feeding habits, but under similar environmental conditions the niche shift between predators was almost identical. For Wissa, the niche breadth was stable at a low level, whereas for Biebrza it fluctuated at values greater than those for Wissa, except for winter 2007. The differences in niche breadth coefficient between the areas suggest that mink feeding habits were related to both river size and environmental factors affecting the availability of each prey group. Similar results for this predator were observed for diet comparison between spring-summer and autumn-winter seasons for individuals occupying small rivers in Białowieża Forest (Jędrzejewska et al. 2001). However, to the best of our knowledge, this study is the first attempt to compare American mink feeding habits under different climatic conditions in winter.

\section{References}

Bartoszewicz, M. and A. Zalewski. 2003. American mink, Mustela vison diet and predation on waterfowl in the Słońsk Reserve, western Poland. Folia Zool. 52: 225-238.

Barreto, G.R., S.P. Rushton, R. Strachan and D.W. Macdonald. 1998. The role of habitat and mink predation in determining the status and distribution of declining populations of water voles in England. Anim. Conserv. 1: 129-137.

Bonesi, L. and D.W. Macdonald. 2004a. Impact of released Eurasian otters on a population of American mink: a test using an experimental approach. Oikos 106: 9-18.

Bonesi, L. and D.W. Macdonald. 2004b. Differential habitat use promotes sustainable coexistence between the specialist otter and the generalist mink. Oikos 106: 509-519.

Bonesi, L. and S. Palazon. 2007. The American mink in Europe: status, impacts and control. Biol. Conserv. 134: 470-483.

Bonesi, L., N. Dunstone and M. O'Connell. 2000. Winter selection of habitats within intertidal foraging areas by mink (Mustela vison). J. Zool. 250: 419-424.

Bonesi, L., P. Chanin and D.W. Macdonald. 2004. Competition between Eurasian otter Lutra lutra and American mink Mustela vison probed by niche shift. Oikos 106: 19-26.

Brzeziński, M. and M. Marzec. 2003. Correction factors used for estimating prey biomass in the diet of American mink Mustela vison. Acta Theriol. 48: 247-254.

Fey, K., P.B. Banks and E. Korpimaki. 2006. Different microhabitat preferences of field and bank voles under manipulated predation risk from an alien predator. Ann. Zool. Fenn. 43: 9-16.

Forman, D.W. 2005. An assessment of the local impact of native predators on an established population of British water voles (Arvicola terrestris). J. Zool. 266: 221-226.
Halliwell, E.C. and D.W. Macdonald. 1996. American mink Mustela vison in the upper Thames catchment: relationship with selected prey species and den availability. Biol. Conserv. 76: 51-56.

Jędrzejewska, B., V.E. Sidorovich, M.M. Pikulik and W. Jędrzejewski. 2001. Feeding habits of the otter and the American mink in Białowieża Primeval Forest (Poland) compared to other Eurasian populations. Ecography 24: 165-180.

Krebs, Ch.J. 1994. Ecology. The experimental analysis of distribution and abundance, 4th edition. Harper Collins College Division, New York.

Krebs, J.R. and N.B. Davies. 2001. Behavioural ecology. An evolutionary approach, 4th edition. Blackwell, Oxford.

Levins, R. 1968. Evolution in changing environments. Princeton University Press, Princeton, NJ.

Lima, S.L., W.A. Mitchell and T.C. Roth. 2003. Predators feeding on behaviourally responsive prey: some implications for classical models of optimal diet choice. Evol. Ecol. Res. 5: 1083-1102.

Lode, T. 1993. Diet composition and habitat use of sympatric polecat and American mink in western France. Acta Theriol. 38: 161-166.

Lode, T. 1995. Activity pattern of polecats Mustela putorius L. in relation to food habits and prey activity. Ethology 100: 295-308.

Lode, T. 1997. Trophic status and feeding habits of the European polecat Mustela putorius L., 1758. Mamm. Rev. 27: 177-184.

Lode, T. 2000. Functional response and area-restricted search of a predator: seasonal exploitation of anurans by European polecat Mustela putorius. Austral. Ecol. 25: 223-231.

Lode, T., J.P. Cormier and D. Le Jacques. 2001. Decline in endangered species as an indication of anthropic pressures: the case of European mink Mustela lutreola western population. Environ. Manage. 28: 727-735.

Maran, T., H. Kruuk, D.W. Macdonald and M. Poloma. 1998. Diet of two species of mink in Estonia: displacement of Mustela lutreola by M. vison. J. Zool. 245: 218-222.

Macdonald, R.A. 2002. Resource partitioning among British and Irish mustelids. J. Anim. Ecol. 71: 185-200.

Macdonald, D.W. and L.A. Harrington. 2003. The American mink: the triumph and tragedy of adaptation out of context. NZ J. Zool. 30: 421-441.

Pianka, E.R. 1973. The structure of lizard communities. Annu. Rev. Ecol. Syst. 4: 53-74.

Rushton, S.P., G.W. Barreto, R.M. Cormack, D.W. Mcdonald and R. Fuller. 2000. Modelling the effects of mink and habitat fragmentation on the water vole. J. Appl. Ecol. 37: 475-490.

Sidorovich, V. 1997. Mustelids in Belarus. Minsk, Zolotoy uley.

Sidorovich, V. 2000. Seasonal variation in the feeding habits of riparian mustelids in river valleys of NE Belarus. Acta Theriol. 45: 233-242.

Sidorovich, V. 2001. Body size and interactions between European and American mink (Mustela lutreola and $M$. vison) in Eastern Europe. J. Zool. 248: 521-527.

Sidorovich, V., D.W. Mcdonald, M. Pikulik and H. Kruuk. 2001. Individual feeding specialization in the European mink, Mustela lutreola and the American mink, M. vison in north-eastern Belarus. Folia Zool. 50: 27-42. 